\title{
Yaş, dental plak miktarı, oral hijyen uygulamaları ve renkli içecekler tüketilmesinin doğal diş rengi üzerindeki etkilerinin değerlendirilmesi
}

\author{
Dilek Nalbant, ${ }^{1}$ Kaan Yerliyurt, ${ }^{2 *}$ \\ Yeşim Göknur Babaç, ${ }^{3}$ Cihan Akçaboy, ${ }^{1}$ \\ Levent Nalbant ${ }^{1}$ \\ ${ }^{1}$ Protetik Diş Tedavisi Anabilim Dalı, Gazi Üniversitesi Diş \\ Hekimliği Fakültesi, Ankara, ${ }^{2}$ Protetik Diş Tedavisi Anabilim \\ Dalı, Gaziosmanpaşa Üniversitesi Diş Hekimliği Fakültesi, \\ Tokat, ${ }^{3}$ Serbest diş hekimi, Ankara, Türkiye
}

\section{Özet}

AmAÇ: Diş dokusundaki yapısal değişimler veya dişlerin yüzeylerinde meydana gelen birtakım birikintiler dişlerde renk değişikliğine sebep olurlar. Bu çalışmanın amacı; bireyin yaşının, dental plak miktarının, diş fırçalama sıklığının, diş ipi kullanma sıklığının, renkli içecekler tüketmesinin diş rengi üzerindeki etkilerinin araştırılmasıdır.

GEREÇ VE YöNTEM: Çalışmaya, gönüllü 202 kişi (85 kadın, 117 erkek) dahil edildi. Bireylere, hazırlanmış olan anketteki sorular yöneltildi. Bireylerin sağ veya sol üst çene ön, yan kesiciler ve kanin dişlerinde ortalama plak indeksleri ölçüldü. Dişlerin renk değerleri dijital renk ölçüm cihazı ile tespit edildi. Korelasyon analizi, Kruskal-Wallis ve Mann-Whitney $\mathrm{U}$ testleri istatistiksel analizler için kullanıldı.

BULGULAR: Bireylerin yaşı arttıkça renk değerleri de daha yüksek bulundu ( $p=0.0001<0.05 ; r=0.391$ ). Ortalama plak indeks değeri arttıkça dişlerin renk değerleri de arttı $(p=0.0001<0.05 ; r=0.255)$. Farklı diş fırçalama sıklığına sahip gruplar arasında renk değerleri bakımından anlamlı farklılık görüldü $(p=0.0001<0.05$, Kruskal-Wallis testi). Farklı diş ipi kullanma sıklığına sahip gruplar arasında renk değerleri bakımından anlamlı farklılık görülmüştür $(p=0.0001<0.05$ Kruskal-Wallis testi). Farklı renkli içecek içme sıklığına sahip gruplar arasında renk değerleri bakımından anlamlı farklılık görülmüştür $(p=0.016<0.05$, Kruskal-Wallis testi).

Sonuç: Bireylerin yaşı arttıkça diş renklerinin koyuluk değerleri de artmaktadır. Ortalama plak indeks değerleri arttıkça diş renkleri daha koyu bulunmuştur. Diş fırçalama ve diş ipi kullanma sıklığının artması bireylerin diş renginin

Makale gönderiliş tarihi: 10 Temmuz 2013; Yayına kabul tarihi: 11 Aralık 2013 *iletişim: Kaan Yerliyurt, Protetik Diş Tedavisi Anabilim Dalı, Gaziosmanpaşa Üniversitesi Diş Hekimliği Fakültesi, Ali Şevki Erek Yerleșkesi, Merkez,

Tokat, Türkiye;

e-posta: kaanyerliyurt@ hotmail.com daha parlak ve açık olmasını sağlamaktadır. Renkli içeceklerin tüketim miktarının artması, diş renklerinin daha koyu ve mat olmasına neden olan faktörlerdendir.

Anahtar Kelimeler: Ağız hijyeni; dişte renk değişikliği; doğal diş rengi; yaş faktörleri; yiyecek ve içecekler

Kaynak Göstermek İçin: Nalbant D, Yerliyurt K, Babaç YG, Akçaboy C, Nalbant L. Yaş, dental plak miktarı, oral hijyen uygulamaları ve renkli içecekler tüketilmesinin doğal diş rengi üzerindeki etkilerinin değerlendirilmesi. Acta Odontol Turc 2014;31(2):89-94.

\section{[Abstract in English is at the end of the manuscript]}

\section{Giriş}

Hastalar günümüzde sağlıklı bir ağzın yanı sıra aynı zamanda mükemmel bir gülümseme talep etmektedirler. ${ }^{1}$ Gülümsemenin bir kişinin interaktif iletişim becerilerinin en önemlilerinden biri olduğu söylenmektedir. ${ }^{1}$ Diş hekimliğinde estetiğin nihai hedefi, güzel görünümlü dişlerin birbirleriyle oranlı olduğu, dişlerin hastanın dişeti, dudakları ve yüzüyle uygun bir biçimde düzenlendiği güzel bir gülümseme oluşturmaktır.² Buna ek olarak, herhangi bir restorasyonda estetik açısından, yüzey formu, saydamlık ve renk parametrelerini dikkate almak gerekir. ${ }^{1-3}$

Dişin koronal kısmındaki dokular mine, dentin ve pulpa dokularıdır. Esas diş rengi, mine ve dentinin ışık saçılması ve emilimi özellikleri ile ilişkilidir. ${ }^{1,4}$ Diş dokusundaki yapısal değişimler veya dişlerin yüzeylerinde meydana gelen birtakım birikintiler dişlerde renk değişikliğine sebep olurlar. Diş renklenmeleri, renklenmenin lokalizasyonu ve etiyolojisine göre ayrılır ve çok faktörlü bir olaydır. Diş renklenmeleri iç kaynaklı veya dış kaynaklı olabilir. 5,6 İç kaynaklı renklenmeler sadece dentini, sadece mineyi veya her iki dokuyu birlikte ilgilendirirken, dış kaynaklı renklenmeler minede meydana gelir. ${ }^{5}$ Yaşlanma, amelogenezis imperfekta, dentinogenezis imperfekta, tetrasiklin renklenmesi, florozis, mine hipoplazileri, kök rezorpsiyonu başıca iç kaynaklı renklenme sebeplerindendir. ${ }^{7}$ Dış kaynaklı renklenmeler, çay, kahve, kırmızı şarap, sigara, kola, metal tuzları ve kötü ağız hijyeni nedeniyle olabilmektedir. ${ }^{5,8-10}$ 
Renk analizi için iki yöntem kullanılmaktadır. Bunlar görsel ve aletli renk analizidir. Görsel renk analizi, bir nesnenin renginin renk standartları ile karşılaştııılmasıdır. Diş hekimliğinde görsel renk analizi renk skalaları kullanılarak yapılmaktadır. ${ }^{11}$ Aletli renk analizi, optik aletlerle nesnenin yansıttığı ışık analiz edilerek yapılmaktadır. Nesnelerin rengi hakkında tutarlı, güvenilir ve miktarsal veri sağlanır. ${ }^{11}$ Aletli renk analizi diş renginin değerlendirme koşullarından ve gözlemcinin deneyiminden bağımsız objektif olarak değerlendirilmesine izin verdiği için çekicidir. ${ }^{12,13}$ Bu yaklaşımla kullanılan aletler spektrofotometreler, kolorimetreler, filme dayalı fotoğraflar ve dijital fotoğraflar olarak sayılabilir. ${ }^{9}$ Doğal dişlerin spektrofotometrik renk analizi görsel renk değerlendirmesiyle kıyaslandığında daha doğru ve daha tekrarlanabilir bulunmuştur (\%83'e karşı \%26.6). ${ }^{14}$

Bu çalışmanın amacı, bireyin yaşının, dental plak miktarının, diş fırçalama sıklığının, diş ipi kullanma sıklığının, renkli içecekler tüketmesinin diş rengi üzerindeki etkilerinin araştııımasıdır.

\section{Gereç Ve Yöntem}

\section{Bireyler}

Yaptığımız epidemiyolojik çalışmadaki bireyler Gazi Üniversitesi Diş Hekimliği Fakültesi kliniklerine gelmiş olan hastalar ve bu fakültede eğitim görmekte olan diş hekimliği öğrencileri arasından seçilmiştir. Bu amaçla düzenlenmiş anket formundaki sorular bireylere sorulmuştur. Bu araştırmaya 85 kadın ve 117 erkek olmak üzere 202 kişi dahil edilmiştir (ortalama yaş 34.4). Bireylerin sağ veya sol üst çene ön kesiciler, yan kesiciler ve kanin dişlerinin orta üçlülerinden ölçümler yapımışıır. Bu dişler kolay görülebilir olmasından dolayı seçilmiştir. Dişlerinde restorasyon bulunan bireyler araştırmaya dahil edilmemiştir.

Araştırma Gazi Üniversitesi Tıp Fakültesi Yerel Etik Kurulu tarafından onaylanmışıı (12/09/2005-209).

\section{Anket}

Bireylere tablo biçiminde hazırlanmış anketteki sorular yöneltilmiştir (Tablo1).

\section{Ortalama plak indeksi}

Löe\&Silness tarafından geliştirilen plak indeksi kullanılmıştır. ${ }^{15}$ Dişeti kenarı dört bölgeye ayrılmıştır (bukkal, lingual, meziyal ve distal). Dört bölgenin herbiri aşağıdaki kriterlere göre 0-3 arasında değerlendirilmiştir.

0 : Dişeti bölgesinde plak yok

1: Serbest dişeti kenarına ve buna bitişik dişe yapışan film

2: Çıplak gözle görülebilen, dişeti kenarındaki dişeti cebi içinde ve/veya bitişik diş yüzeyindeki orta derecedeki eklenti birikimi

3: Dişeti cebi içindeki ve/veya dişeti kenarında ve bitişik diş yüzeyindeki fazla miktardaki yumuşak madde.

Bir diş için ortalama plak indeksi; meziyal, distal, lingual ve vestibül kısımlarına verilen puanların toplanarak, dörde bölünmesi ile bulunmuştur. Bir kişinin plak indeksi ise bütün dişlerin aldığı puan toplamının diş sayısına bölünmesiyle bulunmuştur.

\section{Renk seçimi}

Bu çalışmada, dişlerdeki renk dağılımı bir cihaz yardımıyla değerlendirilmiştir. Bu amaçla piyasada mevcut olan bir dijital renk ölçüm cihazı (ShadeScan, Cynovad, Montréal, Kanada) kullanılmıştır. ShadeScan cihazı, üzerinde $1.5 \times 2$ inç büyüklüğünde LCD ekranı olan kablolu bir el aleti ve bu el aletinin üzerine oturduğu otomatik kalibrasyon sağlayan üniteden oluşmaktadır. ShadeScan herhangi bir aydınlatma koşulunda kullanılabilir, çünkü halojen ışık, ortam ışığından etkilenmeyecek miktarda parlaktır. ${ }^{16}$

Bilgisayar-destekli renk seçimi aynı kişi tarafından yapılmıştır. Her bir seçime başlarken, aletin ısınması üretici firmanın önerisi doğrultusunda beklenmiştir. Bireylerin ölçümler sırasında başlarını tetiyere yaslamaları ve ağızlarını hafifçe açmaları istenmiştir. Dişlerin insizal şeffaflıklarından doku yansımasına bağı olarak dilin maksillanın ön bölgesine dayanması yanlış ölçümlere neden olabileceğinden; dilin istirahat pozisyonunda olması sağlanmıştır. Ölçümler sırasında ünitin ışığı kapalı tutulmuştur. Ölçüm başıIğı mümkün olduğunca dişin yüzeyine dik olarak yerleştirilmiştir. Ölçümlere ön kesici

Tablo 1. Anket soruları ve cevap seçenekleri

\begin{tabular}{lcccc}
\hline Sorular & \multicolumn{4}{c}{ Cevaplar } \\
\hline 1) Yaşınız? & 17-25 yaş & $26-40$ yaş & $41-55$ yaş & 55 yaş üstü \\
2) Dişlerinizi hangi sıklıkla fırçalarsınız? & Günde 2 kez veya daha fazla & Günde 1 defa & Nadiren & Hiç fıç̧alamam \\
3) Ortalama diş ipi kullanma sıkıı̆ınız nedir? & Günde 2 kez veya daha fazla & Günde 1 defa & Nadiren & Hiç kullanmam \\
4) Renkli içecek içme sıklığınız nedir? & Günde 2 kez veya daha fazla & Günde 1 defa & Nadiren & Hiç içmem \\
\hline
\end{tabular}


dişlerden başlanmıştır. ShadeScan cihazı kullanılırken, istenilen dişin renkli LCD ekran üzerinde yer alan dikdörtgen sahanın ortasında olmasına dikkat edilmiştir. LCD ekran üzerinde dişin görüntüsü odaklandıktan sonra dişin görüntüsü alınmıştır. Ölçümlerin yapılmasından sonra elde edilen veriler bilgisayara aktarılmıştır. Dişlerin farklı bölgelerinin rengi cihazın kendi yazııım programı kullanılarak belirlenmiş ve veriler kaydedilmiştir. Her bir diş için orta üçlünün rengi Vitapan 3D Master (Vita Zahnfabrik H. Rauter Gmbh \& Co. KG, Bad Säckingen, Almanya) renk skalasına göre belirlenmiştir.

\section{İstatistiksel analiz}

Bireylerin yaşı, plak indeksi değerleri ile dişlerin renk değerleri arasındaki ilişki korelasyon analizi ile belirlenmiştir. Bireylerin diş fırçalama sıklıkları, diş ipi kullanma sıklıkları, renkli içecek tüketim sıklıkları ile dişlerin renk değerleri arasında anlamlı farklııı olup olmadığı Kruskal-Wallis testi ile belirlenmiştir. Hangi alt gruplar arasında farklılık olduğu Mann-Whitney $U$ testi ile yapılan ikili karşılaştırmalar sonucu belirlenmiştir.

\section{BULGULAR}

Bireyler yaş gruplarına göre; 17-25, 26-40, 41-55 yaş arası ve 55 yaş üstü olmak üzere 4 gruba ayrılmışlardır (Tablo 2).

Bireylerin ortalama yaş, ortalama plak indeksi, ortalama diş fırçalama alışkanlığı, ortalama diş ipi kullanma alışkanlığı, renkli içeceklerin tüketim ortalaması değerleri ve diş rengi ile olan ilişkileri aşağıda sırasıyla verilmiştir.

\section{Ortalama yaş ve ortalama plak indeksi}

Bireylerin minimum, maksimum, ortalama yaş ve plak indeksi değerleri Tablo 3'te verilmiştir.

Bireylerin yaş değerleri ile dişlerinin orta üçlülerindeki renk değerleri arasında anlamlı bir ilişki görüldü $[p=0.0001<0.05 ; r=0.391$ (Korelasyon analizi)]. Yaş değeri arttıkça orta üçlülerdeki renk değerleri de daha yüksek bulundu.
Tablo 2. Bireylerin yaş gruplarına göre dağııımı

\begin{tabular}{lcc}
\hline Yaş grupları & $\mathbf{n}$ & $\%$ \\
\hline $17-25$ & 88 & 43.6 \\
$26-40$ & 49 & 24.3 \\
$41-55$ & 49 & 24.3 \\
$55+$ & 16 & 7.9 \\
Toplam & 202 & 100.0 \\
\hline
\end{tabular}

(n: sayı)

Tablo 3. Bireylerin yaş ve plak indeksi değerleri

\begin{tabular}{lcc}
\hline İstatistiksel veriler & Yaş & Plak indeksi \\
\hline Ortalama & 34.4 & 0.510 \\
Orta değer & 30.0 & 0.395 \\
Standart sapma & 14.3 & 0.444 \\
Minimum & 17 & 0 \\
Maksimum & 84 & 2.875 \\
$\mathrm{n}$ & 202 birey & 606 alan \\
\hline (n: sayı) & &
\end{tabular}

Ortalama plak indeksi değerleri ile dişlerin orta üçlülerindeki renk değerleri arasında anlamlı bir ilişki görüldü [ $p=0.0001<0.05 ; r=0.255$ (Korelasyon analizi)]. Plak indeks değeri arttıkça orta üçlülerindeki renk değerleri de arttı.

\section{Ortalama diş fırçalama alışkanlığı, diş ipi kullanma alışkanlığı ve renkli içecek tüketimi}

Bireyler diş fırçalama sıklıklarına, diş ipi kullanma sıklıklarına ve renkli içecek tüketimlerine göre Tablo 4'te belirtildiği şekilde sınıflandırımışlardır.

\section{Diş fırçalama sıklığı ve renk değerleri ilişkisi}

Farklı diş fırçalama sıklığına sahip gruplar arasında renk değerleri bakımından anlamlı farklılık görüldü $(p=0.0001<0.05$, Kruskal-Wallis testi). Hangi gruplar arasında farklılık olduğu Mann-Whitney $U$ testi ile yapılan ikili karşılaştırmalar sonucu belirlendi:

Tablo 4. Bireylerin diş fırçalama, diş ipi kullanma ve renkli içecek tüketim sıklıkları

\begin{tabular}{lccc}
\hline & $\begin{array}{c}\text { Diş fırçalama sıkı̆̆ı } \\
\mathrm{n}(\%)\end{array}$ & $\begin{array}{c}\text { Diş ipi kullanma sıkı̆̆ı } \\
\mathrm{n}(\%)\end{array}$ & $\begin{array}{c}\text { Renkli içeceklerin tüketim sıklı̆̆ı } \\
\mathrm{n}(\%)\end{array}$ \\
\hline Hiçbir zaman & $0(0)$ & $133(65.8)$ & $1(0.5)$ \\
Nadiren & $17(8.4)$ & $51(25.2)$ & $15(7.4)$ \\
Günde 1 defa & $75(37.1)$ & $14(6.9)$ & $33(16.3)$ \\
Günde 2 defa veya daha fazla & $110(54.5)$ & $4(2.0)$ & $153(75.7)$ \\
Toplam & $202(100.0)$ & $202(100.0)$ & $202(100.0)$ \\
\hline
\end{tabular}


Nadiren-günde 1 defa diş fırçalayan gruplar arasında dişlerin orta üçlülerindeki renk değerleri açısından anlamlı farklılık görüldü $(p=0.0001<0.0166$, Bonferroni düzeltmesi, Mann-Whitney $U$ testi). Nadiren grubunda orta üçlülerdeki renk değerleri daha yüksek görüldü.

Nadiren-günde 2 veya daha fazla grupları arasında dişlerin orta üçlülerindeki renk değerleri açısından anlamlı farklıılık görüldü ( $p=0.0001<0.0166$, Mann-Whitney $\mathrm{U}$ testi). Nadiren grubunda orta üçlülerdeki renk değerleri daha yüksek görüldü.

Günde 1 defa-günde 2 defa veya daha fazla grupları arasında dişlerin orta üçlülerindeki renk değerleri açısından anlamlı farklılık görüldü $(p=0.001<0.0166$, MannWhitney $U$ testi). Günde 1 defa grubunda orta üçlülerdeki renk değerleri daha yüksek görüldü.

\section{Diş ipi kullanma sıklığı ve renk değerleri ilişkisi}

Araştırmaya katılan bireylerden elde edilen sonuçlarda diş ipi kullanma alışkanlıkları incelendiğinde günde 2 kez veya daha fazla sıklıkta diş ipi kullanan bireylerin araştırmaya katılanların yaklaşık \%2'sini oluşturduğu bulundu. Bu grubun istatistiksel olarak diğer gruplarla karşılaştırımasının bilimsel olarak sağlıklı sonuçlar vermeyeceği düşünüldüğünden bu grup günde bir kez diş ipi kullanan grupla birleştirildi ve başığı 'günde 1 defa veya daha fazla' olarak değiştirildi.

Farklı diş ipi kullanma sıklı̆ına sahip gruplar arasında renk değerleri bakımından anlamlı farklılık görüldü $(p=0.0001<0.05$, Kruskal-Wallis testi). Hangi gruplar arasında farklılık olduğu Mann-Whitney $U$ testi ile yapılan ikili karşılaşı ırmalar sonucu belirlendi:

Hiçbir zaman ve nadiren diş ipi kullanan gruplar arasında dişlerin orta üçlülerindeki renk değerleri açısından anlamlı farklılık görüldü ( $p=0.0001<0.0166$, Bonferroni düzeltmesi, Mann-Whitney $U$ testi). Hiçbir zaman grubunda dişlerin orta üçlülerindeki renk değerleri daha yüksek bulundu.

Hiçbir zaman ve günde 1 defa veya daha fazla diş ipi kullanan gruplar arasında renk değerleri açısından anlamlı farklılık görülmedi ( $p=0.028>0.0166$, Mann-Whitney $\mathrm{U}$ testi). Hiçbir zaman grubunda istatistiksel olarak anlamlı olmamakla birlikte dişlerin orta üçlülerindeki renk değerleri daha yüksek bulundu.

Nadiren ve günde 1 defa veya daha fazla diş ipi kulIanan gruplar arasında yapılan ikili karşılaştırmalarda dişlerin orta üçlülerindeki renk değerleri açısından anlamlı farklılık görülmedi ( $p=0.858>0.0166$, Mann-Whitney $U$ testi). Günde 1 kez veya daha fazla diş ipi kullanan grupta istatistiksel olarak anlamlı olmamakla birlikte dişlerin orta üçlülerindeki renk değerleri daha yüksek bulundu.

\section{Renkli içecek içme sıklığı ve renk değerleri ilişkisi}

Farklı renkli içecek içme sıklığına sahip gruplar arasında renk değerleri bakımından anlamlı farklılık görülmüştür ( $p=0.016<0.05$, Kruskal-Wallis testi). Hangi gruplar arasında farklılık olduğu Mann-Whitney $U$ testi ile yapılan ikili karşılaştırmalar sonucu belirlendi:

Nadiren ve günde 1 defa grupları arasında ( $p=0.022>0.0166$, Bonferroni düzeltmesi, Mann-Whitney $\mathrm{U}$ testi) ve günde 1 defa ve günde 2 defa veya daha fazla grupları arasında $(p=0.722>0.0166$, Mann-Whitney $U$ testi) yapılan ikili karşılaştırmalarda dişlerin orta üçlülerindeki renk değerleri açısından anlamlı farklılık görülmedi.

Nadiren ve günde 2 defa veya daha fazla renkli içecek içen gruplar arasında dişlerin orta üçlülerindeki renk değerlerinde anlamlı farklılık görüldü ( $\mathrm{p}=0.004<0.0166$, Mann-Whitney $U$ testi). Günde 2 defa veya daha fazla grubunda dişlerin orta üçlüsündeki renk değerleri daha yüksek görüldü.

\section{TARTIŞMA}

Araştırmamızda aletli renk seçim yöntemi kullanıımıştır. Kullanılacak cihaz olarak dijital görüntüyü bir bilgisayar analiz programıyla birleştiren ShadeScan seçilmiştir.

Dozic ve ark. ${ }^{17}$ araştırmalarında standart koşullar altında spektrometre ve dijital kamera ile renk ölçümünün yapılması arasında performans açısından bir fark olmadığını belirtmişlerdir. Aynı hasta için kullanımda ShadeScan'in tekrarlanabilirlik açısından doğruluğu en fazla olan cihaz olduğu sonucuna varmışlardır. Ayrıca in vitro olarak da ShadeScan, Ikam ve Easyshade'in en güvenilir cihazlar olduğunu gözlemlemişlerdir. ${ }^{17}$

Renk belirlemek için renk ölçüm cihazlarının kullanımı, sayısalaştıılabilir, hızlı ve objektif sonuçlar verdiği için görsel yönteme göre daha avantajlı sayılmaktadır. ${ }^{18}$

Çalışmamızda dişlerin orta üçlülerinden renk seçimi yapılmıştır. Dişin orta üçlüsünün dişin renginin en iyi temsil edildiği bölge olarak tarif edildiği çalışmalar mevcuttur. Araştırmacılar, dişin insizal bölgesinin genellikle saydam olduğunu ve dişin arka planından etkilenmekte olduğunu, servikal üçlünün renginin ise dişetinden saçılan ışık tarafından değiştiğini belirtmişlerdir. 1,19

Bireyin yaşının artmasıyla beraber dişlerin görünümünde birtakım değişiklikler olduğu bilinmektedir. Bu konuda yapılan araştırmalar mevcuttur. 16,20,21 Yaşlı dentin veya sklerotik dentin daha koyudur (yoğunluk değeri yüksek, parlaklık değeri düşüktür). Genç dentin daha kırmızı-sarıyken yaşlı dentin daha çok yeşil-mavidir. ${ }^{22}$ İleri yaşlarda dentin kırmızı-sarıdan sarıya doğru bir renk değişimine uğrasa da yaşı dişlerin rengi genç dişlerden daha kırmızıdır. Çünkü aşınma sebebiyle dentinin kırmızılığını örtebilecek çok ince ve parlak bir mine 
tabakası vardır. ${ }^{11}$ Gozalo-Diaz ve ark. ${ }^{20}$ yaptıkları çalışmada; bireylerde yaş arttıkça ön kesicilerin daha koyu, daha fazla kırmızı ve daha sarı olduklarını bildirmişlerdir. Hartmann ve ark. ${ }^{21}$ yaptıkları çalışmada; yaşlı bireylerden (ortalama yaş: 67.3) oluşturdukları çalışma grubu ile genç bireylerden (ortalama yaş: 25.8) oluşturdukları kontrol grubu arasında Vitapan 3D-Master renk skalasıyla renk analizi yapmışlardır. Yaşlı bireylerdeki ortalama renk tonu değerini 3.4 ve genç bireylerde ise 2.5 olarak bulmuşlardır. Çalışmamızda ortaya çıkan sonuçlara göre; bireylerin yaş değerleri ile dişlerinin orta üçlülerindeki renk değerleri arasında anlamlı bir ilişki görülmüştür. Yaş değeri arttıkça orta üçlülerdeki renk değerleri de daha yüksek olmuştur. Araştırmamızda bireyin yaş faktörüne bağlı olarak bulduğumuz sonuçlar yukarıda belirtilen çalışmalardaki sonuçlara paralellik göstermektedir.

Yapılan bir çalışmada, papain ve bromelin içerikli diş macunu ile içeriğinde bu maddeleri bulundurmayan bir başka diş macununun diş yüzeylerini temizleme etkinlikleri kıyaslanmıştır. ${ }^{10}$ Her iki grupta da diş macunları ile düzenli şekilde fırçalama yapıldıktan sonra dişlerin renkleri öncesine göre daha parlak bulunmuştur. Papain ve bromelin içerikli diş macunu grubunda (test grubu) dişlerin renkleri öncesine göre, istatistiksel olarak anlamlı derecede daha fazla parlak bulunmuştur. ${ }^{10}$ Bahsedilen çalışmaya benzer şekilde değişik diş macunlarının temizleyici etkilerinin araştırıldığı, birbirleriyle kıyaslandığı birçok çalışma mevcuttur. ${ }^{23-25} \mathrm{Bu}$ çalışmaların ortak yönü, diş macunlarının hepsinin değişen miktarlarda olmak üzere diş yüzeylerindeki lekeleri çıkarmalarıdır.

Çalışmamızda diş fırçalama sıklıkları daha fazla olan bireylerde, diş renkleri daha açık bulunmuştur. Bu sonuçlar, diş macunlarının temizleyici etkilerinin araştırıldığı çalışmaların sonuçlarıyla paralellik göstermektedir.

Benzer şekilde çalışmamızda diş ipi kullanma sıklıkları daha fazla olan bireylerde, diş renkleri daha açık bulunmuştur. Hiçbir zaman ve nadiren diş ipi kullanan gruplar arasında dişlerin orta üçlülerindeki renk değerleri açısından anlamlı farklılık görülürken, hiçbir zaman ve günde 1 kez veya daha fazla diş ipi kullanan gruplar arasında dişlerin orta üçlülerindeki renk değerleri açısından anlamlı farklılık görülmemiştir. Bu sonuç günde 1 kez veya daha fazla diş ipi kullanan gruba dahil birey sayısının az oluşundan kaynaklanmış olabilir.

Renkli içecek tüketiminin bireylerin diş rengine etkisini inceleyen çalışmalar mevcuttur. ${ }^{9,26,27}$ Sarı ve ark. ${ }^{9}$ çocukların tükettiği yiyecek ve içeceklerin süt ve daimi diş rengine etkilerini inceledikleri çalışmalarında, çocukların günlük tükettiği farklı tipteki yiyecek ve içeceklerin diş minesinin rengini değiştirdiğini belirtmişlerdir. Çalışmalarında en fazla boyanma değerlerinin gazlı içecek ve meyve suyunda olduğunu belirtmişlerdir. Çalışmamızda renkli içeceklerin tüketim sıklığının fazla olduğu birey- lerde diş renklerinin daha koyu olduğu gözlenmiştir. ÇaIışmamızın sonucunu destekleyici sonuçlara sahip olan çalışmalar mevcuttur. ${ }^{26,27}$ Akman ve ark. ${ }^{26}$ yaptıkları çaIışmada; 4 farklı düşük ısı porseleninin renk stabilitesine çay, kahve ve sigara dumanının etkisini incelemişlerdir. Örnekleri 1, 10, 20, 30, 45 gün süreyle çay, kahve ve sigara dumanına maruz bırakmışlardır. Örneklerden fırçalama yaparak ve yapmayarak renk ölçümleri yapmışlardır. Çalışmalarının sonucunda örneklerin fırçalanması sonucu porselendeki renklenmelerin önemli ölçüde azaldığını belirtmişlerdir. Tüm boyayıcı ajanların 45 güne kadar renklenmeyi artırdıklarını bildirmişlerdir. Buna ilaveten; çayın tüm porselenlerde hafif bir renklenmeye yol açarken, kahve ve sigara dumanının klinik olarak fark edilebilir bir renklenmeye neden olduklarını belirtmişlerdir. ${ }^{26}$ Köksal\&Dikbaş ${ }^{27}$ iki farklı marka porselen dişlerin ve üç farklı marka akrilik protez dişlerin renk kararlıığını değerlendirmek amacıyla yaptıkları çalışmada; örnekleri kahve, çay ve kola solüsyonlarında 1 gün, 1 hafta, 2 hafta, 4 hafta süreyle bekletmişlerdir. ÇaIsşmalarının sonucunda her grup için, renk koyuluğunun miktarı renkli içeceklerde bekleme süreleri ile orantılı olarak artmıştır. Bu çalışmaların sonuçlarında renkli içeceğe maruz kalma süresi arttıkça dişlerin renkleri daha koyu bulunmuştur. Bu sonuçlar araştırmamızın sonuçlarına paralelellik göstermektedir.

\section{Sonuç}

Yapılan bu çalışmanın sonucunda; bireylerin yaşının, dental plak miktarının ve renkli içecek tüketim sıklığının artmasının diş renginde koyuluğun ve matlığın artmasına sebep olduğu gözlenmiştir. Diş fırçalama sıklığının ve diş ipi kullanma sıklığının artması ise diş rengi üzerinde olumlu etki göstermiş ve dişlerin daha parlak ve açık renkli olmalarını sağlamıştır.

Çıkar çatışması: Yazarlar bu çalışmayla ilgili herhangi bir çıkar çatışmalarının bulunmadığını bildirmişlerdir.

\section{KAYNAKLAR}

1. Joiner A. Tooth colour: a review of the literature. J Dent $2004 ; 32$ Suppl 1:3-12.

2. Mayekar SM. Shades of a color. Illusion or reality? Dent Clin North Am 2001;45:155-72, vii.

3. Terry DA, Geller W, Tric O, Anderson MJ, Tourville M, Kobashigawa A. Anatomical form defines color: function, form, and aesthetics. Pract Proced Aesthet Dent 2002;14:59-67; quiz 68.

4. ten Bosch JJ, Coops JC. Tooth color and reflectance as related to light scattering and enamel hardness. J Dent Res 1995;74:374-80.

5. Özel Y, Özel E, Attar N, Aksoy G. Diş hekimliğinde beyazlatma. EÜ Diş Hek Fak Derg 2007;28:33-40.

6. Nathoo SA. The chemistry and mechanisms of extrinsic and intrinsic discoloration. J Am Dent Assoc 1997;128 Suppl:6S-10S.

7. Watts A, Addy M. Tooth discolouration and staining: a review of the literature. Br Dent J 2001;190:309-16.

8. Yap AU, Wattanapayungkul P. Effects of in-office tooth whiteners on hardness of tooth-colored restoratives. Oper Dent 2002;27:137-41. 
9. Sarı ME, Koyutürk AE, Çankaya S. Çocukların tükettiği yiyecek ve içeceklerin süt ve daimi diş rengine etkisi. Cumhuriyet Dent $\mathrm{J}$ 2011;14:18-23.

10. Chakravarthy P, Acharya S. Efficacy of extrinsic stain removal by novel dentifrice containing papain and bromelain extracts. J Young Pharm 2012;4:245-9.

11. Keyf $F$, Uzun G, Altunsoy S. Diş hekimliğinde renk seçimi. Hacettepe Üniv Diş Hek Fak Derg 2009;33:52-8.

12. Ishikawa-Nagai S, Ishibashi K, Tsuruta O, Weber HP. Reproducibility of tooth color gradation using a computer color-matching technique applied to ceramic restorations. J Prosthet Dent 2005;93:129-37.

13. Analoui M, Papkosta E, Cochran M, Matis B. Designing visually optimal shade guides. J Prosthet Dent 2004;92:371-6.

14. Paul S, Peter A, Pietrobon N, Hämmerle $\mathrm{CH}$. Visual and spectrophotometric shade analysis of human teeth. J Dent Res 2002;81:578-82.

15. Silness J, Loe H. Periodontal disease in pregnancy II. Correlation between oral hygiene and periodontal condition. Acta Odontol Scand 1964;22:121-35.

16. Bayindir F, Gozalo-Diaz D, Kim-Pusateri S, Wee AG. Incisal translucency of vital natural unrestored teeth: a clinical study. J Esthet Restor Dent 2012;24:335-43.

17. Dozić A, Kleverlaan CJ, El-Zohairy A, Feilzer AJ, Khashayar G. Performance of five commercially available tooth color-measuring devices. J Prosthodont 2007;16:93-100.

18. Turgut $S, B a g ̆ ı s ̧ ~ B$. Diş hekimliğinde renk ve renk ölçüm yöntemleri. Atatürk Üniv Diş Hek Fak Derg 2012;Suppl 5:65-75

19. Okubo SR, Kanawati A, Richards MW, Childress S. Evaluation of visual and instrument shade matching. J Prosthet Dent 1998;80:642-8.

20. Gozalo-Diaz D, Johnston WM, Wee AG. Estimating the color of maxillary central incisors based on age and gender. J Prosthet Dent 2008; $100: 93-8$

21. Hartmann R, Müller F. Clinical studies on the appearance of natural anterior teeth in young and old adults. Gerodontology 2004;21:10-6.

22. Hasegawa A, Ikeda I, Kawaguchi S. Color and translucency of in vivo natural central incisors. J Prosthet Dent 2000;83:418-23.

23. Creeth JE, Price KS, Wicks MA. The stain removal performance of a new anti-hypersensitivity dentifrice. J Clin Dent 2006;17:106-11.

24. Pickles MJ, Evans M, Philpotts CJ, Joiner A, Lynch RJ, Noel N, et al. In vitro efficacy of a whitening toothpaste containing calcium carbonate and perlite. Int Dent J 2005;55 Suppl 1:197-202.

25. Collins LZ, Naeeni M, Schäfer F, Brignoli C, Schiavi A, Roberts J, et al. The effect of a calcium carbonate/perlite toothpaste on the removal of extrinsic tooth stain in two weeks. Int Dent J 2005;55 Suppl 1:179-82.

26. Akman S, Gür E, Avunduk MC, Aykent F. In vitro effect of tea, coffee, and cigarette smoking on color of low-fusing porcelains. Turkiye Klinikleri J Dental Sci 2010;16:223-9.

27. Koksal T, Dikbas I. Color stability of different denture teeth materials against various staining agents. Dent Mater J 2008;27:139-44.
Evaluation of the impact of age, the amount of dental plaque, oral hygiene applications and consumption of colored drinks on the natural tooth color

\begin{abstract}
OвJECTIVE: Structural changes on dental tissues or accumulation of debris on the tooth surfaces may cause tooth discoloration. The purpose of this study was to evaluate the effects of individual's age, amount of dental plaque, frequency of tooth brushing, frequency of dental floss use and consumption of colored beverage on tooth color change.
\end{abstract}

Materials and Method: 202 volunteers (85 female, 117 male) were included in the study. Individuals were asked to fill in questionnaires. The mean plaque index in the upper right or left central, lateral incisor and canine was measured. Color values of the teeth were measured by using a digital color measurement device. Correlation analysis, Kruskal-Wallis and Mann-Whitney $U$ tests were used for the statistical analyses.

RESULTS: Color saturation values increased with the increase in the individuals' age $(p=0.0001<0.05 ; r=0.391)$. Color saturation values increased also with the increase of the mean plaque index values $(p=0.0001<0.05 ; r=0.255)$. Significant differences in terms of color values were observed between groups with different tooth brushing frequencies $(p=0.0001<0.05$, Kruskal-Wallis test). Significant differences in terms of color values was observed also between groups with different dental floss usage frequencies $(p=0.0001<0.05$, Kruskal-Wallis test). Significant differences in terms of color values were observed also between groups with different colored beverage consumption frequencies $(p=0.016<0.05$, Kruskal-Wallis test).

ConcLusion: The saturation of the tooth color increases with an increase of the age. Increase in frequencies of tooth brushing and dental floss usage provides a brighter and lighter tooth color. Increase in consumption of colored beverages causes a darker and lusterless tooth color.

KEYWORDS: Age factors; food and beverages; natural tooth color; oral hygiene; tooth discoloration 